\title{
Ultrasonographic study of fetal facial profile markers during the first trimester
}

\author{
Chunya $\mathrm{Ji}^{\dagger}$, Xiaoli Jiang ${ }^{\dagger}$, Linliang Yin ${ }^{*}, X$ Xuedong Deng ${ }^{*}$, Zhong Yang, Qi Pan, Jun Zhang and Qing Liang
}

\begin{abstract}
Background: To establish reference ranges of fetal facial profile markers and study their correlations with crownrump length (CRL) during the first trimester $\left(11 \sim 13^{+6}\right.$ weeks' gestation) in a Chinese population.

Methods: Ultrasonographic images of measuring fetal nuchal translucency (NT) were retrospectively selected randomly in normal fetuses whose parents were both Chinese. The facial markers included inferior facial angle (IFA), maxilla-nasion-mandible (MNM) angle, facial maxillary angle (FMA) and profile line (PL) distance. These markers were measured through ViewPoint 6 software by two experienced sonographers.

Results: Three hundred and eighty fetuses were selected. The ICCS (95\% Cl) of intra-operator 1 reproducibility of IFA, MNM angle, FMA, PL distance were 0.944 (0.886 0.973), 0.804 (0.629 0.902), 0.834 (0.68 0.918) and 0.935 (0.868 0.969), respectively. The ICCS $(95 \% \mathrm{Cl})$ of intra-operator 2 reproducibility of IFA, MNM angle, FMA, PL distance were 0.931 (0.857 0.967), 0.809 (0.637 0.904), $0.786(0.600 \sim 0.892)$ and 0.906 (0.813 0.954), respectively. The ICCs $(95 \% \mathrm{Cl})$ of inter-operator reproducibility of IFA, MNM angle, FMA, PL distance were 0.885 (0.663 0.953), 0.829 (0.672 0.915), $0.77(0.511 \sim 0.891)$ and $0.844(0.68 \sim 0.925)$, respectively. The average \pm SD of IFA, MNM angle, FMA and PL distance were $80.2^{\circ} \pm 7.25^{\circ}, 4.17^{\circ} \pm 1.19^{\circ}, 75.36^{\circ} \pm 5.31^{\circ}, 2.78 \pm 0.54 \mathrm{~mm}$, respectively. IFA and PL distance significantly decreased with CRL, while MNM angle and FMA significantly increased with CRL.

Conclusions: It was feasible to measure fetal facial markers during the first trimester. In Chinese population, the reference ranges of IFA, MNM angle, FMA and PL distance were $80.2^{\circ} \pm 7.25^{\circ}, 4.17^{\circ} \pm 1.19^{\circ}, 75.36^{\circ} \pm 5.31^{\circ}, 2.78 \pm 0.54$ $\mathrm{mm}$, respectively, and the measurements were found to correlate with CRL.
\end{abstract}

Keywords: First trimester, Fetus, Facial profile, Marker, Ultrasonography

\section{Background}

Fetal facial malformations mainly include cleft lip and palate (CLP), micrognathia, maxillary dysplasia, and absence of nasal bone, which are closely related to some chromosomal abnormalities or genetic syndrome [1,2]. With the rapid development of ultrasound technology and the continuous accumulation of sonographers' experience in recent years, the majority of CLP can be

\footnotetext{
*Correspondence: yllsznthello@hotmail.com; xuedongdeng@163.com Chunya Ji and Xiaoli Jiang are co-first authors.

${ }^{+}$Chunya Ji and Xiaoli Jiang contributed equally to this manuscript. Center for Medical Ultrasound, The Affiliated Suzhou Hospital of Nanjing Medical University, Suzhou Municipal Hospital, No. 26 Daogian Street, 215002 Suzhou, Jiangsu, China
}

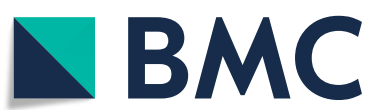

diagnosed mainly during the second and third trimester. Severe micrognathia can be subjectively judged based on the shape of fetal facial profile and also be assessed by measuring the mandible length [3]. However, if fetal facial malformations can be diagnosed during the first trimester ( $11 \sim 13^{+6}$ weeks' gestation), healthcare providers and parents will have enough time to evaluate fetal prognosis, such as performing chorionic villus sampling (CVS) or early anatomic survey, which is of great clinical importance. Actually most facial structures of the fetus have been differentiated during the first trimester [4], so it is feasible to evaluate fetal facial structure during the first trimester [5]. The guideline issued in 2013 by International Society of Ultrasound in Obstetrics and

(c) The Author(s). 2021 Open Access This article is licensed under a Creative Commons Attribution 4.0 International License, which permits use, sharing, adaptation, distribution and reproduction in any medium or format, as long as you give appropriate credit to the original author(s) and the source, provide a link to the Creative Commons licence, and indicate if changes were made. The images or other third party material in this article are included in the article's Creative Commons licence, unless indicated otherwise in a credit line to the material. If material is not included in the article's Creative Commons licence and your intended use is not permitted by statutory regulation or exceeds the permitted use, you will need to obtain permission directly from the copyright holder. To view a copy of this licence, visit http://creativecommons.org/licenses/by/4.0/. The Creative Commons Public Domain Dedication waiver (http://creativecommons.org/publicdomain/zero/1.0/) applies to the data made available in this article, unless otherwise stated in a credit line to the data. 
Gynecology (ISUOG) [6] pointed out that it was crucial to observe the fetal facial profile. However, prenatal diagnosis of fetal facial abnormalities is still challenging in the first trimester around the world, and a series of simple, reliable and reproducible objective parameters are still lacking. In this study, fetal facial markers including inferior facial angle (IFA), maxilla-nasion-mandible (MNM) angle, facial maxillary angle (FMA) and profile line (PL) distance, were measured in fetal facial midsagittal section during the first trimester. The aim of the present study was to establish the reference range for each marker in Chinese population and analyze their correlation with CRL during the first trimester.

\section{Methods}

\section{Study subjects}

Images of the first trimester ultrasound screening peformed in the Affiliated Suzhou Hospital of Nanjing Medical University between August 2017 and July 2019, which best met inclusion criteria and have high recognizable structure, were retrospectively selected. The pregnancy outcome was followed-up by the Suzhou Maternal-children health care system.

The inclusion criteria were as follows: (1) both parents of the fetus were Chinese; (2) pregnancies with significant maternal complications were excluded; (3) singleton pregnancy; (4) fetuses with normal ultrasound findings and normal follow-up outcomes; (5) the selected twodimensional ultrasound (2D-US) images were the standard mid-sagittal section for measuring nuchal translucency (NT) thickness, which met the standardized protocol at $11 \sim 13^{+6}$ weeks' gestation of the Fetal Medicine Foundation (FMF). The forehead, nasal bone, palate, mandible, upper lip, lower lip and other structures should be clearly displayed in this section.

The study was approved by the Ethics Committee of Suzhou Municipal Hospital.

\section{Equipment and software}

A Philips Affiniti70 and a GE Voluson E10 fourdimensional (4D) color ultrasound machines were utilized in this study; each was equipped with a convex probe of C9-2 and C5-1, with the frequency of $2 \sim$ $9 \mathrm{MHz}$ and $1 \sim 5 \mathrm{MHz}$, respectively. The images obtained by transabdominal ultrasound examination were imported into the ultrasound workstation software, ViewPoint 6 in DICOM (Digital Imaging and Communications in Medicine) format. In addition, fetal facial markers were measured through ViewPoint 6.

\section{Definition of the markers}

IFA [7] was defined as the angle between the line orthogonal to the vertical part of the forehead at the level of the synostosis of the nasal bone and the line joining the tip of the mentum to the most anterior point of the more protruding lip (Fig. 1). MNM angle [8] was defined as the angle between maxilla-nasion line and mandible-nasion line in the mid-sagittal section (Fig. 2), and the nasion [9] was defined as the most anterior point at the intersection of the frontal and nasal bone. FMA [10] was the angle between the line overlying the maxilla and the line across mentum tip and upper lip (Fig. 3). The FPL [9] was defined as the line that passed through the middle point of the anterior border of the mandible and the nasion. PL distance [9] was the perpendicular distance from the facial profile line (FPL) to the outer border of the forehead (Fig. 4).

\section{Measurement of the markers}

Fetal facial markers (IFA, MNM angle, FMA, PL distance) were measured through ViewPoint 6 software by two experienced sonographers, who had obtained the FMF certification for NT scan. The average value of each marker was taken after three measurements. Generally speaking, it takes every 1.5-2 min to measure each of the four markers once, and every 5-6 min for three times.

\section{Statistical analysis}

The analysis was performed by SPSS21.0 (Chicago, IL, USA) and Graphpad Prism8.0. The intraclass correlation coefficient (ICC) and Bland-Altman analysis [11] were used to assess intra-operator and inter-operator reproducibility. Bland-Altman mean and $95 \%$ limits of agreement (LOA) were constructed. The reference range of the data with a Gaussian distribution was expressed by mean \pm 1.96standard deviation (SD). The reference range of the data without a Gaussian distribution was expressed by Median (Inter-Quartile Range). Pearson correlation analysis and univariate regression analysis investigated the correlation between fetal facial markers and CRL.

\section{Results}

Among 3520 fetuses who underwent the first trimester ultrasound screening, 380 were selected because they met the inclusion criteria. The successful rate of measuring all four facial markers is almost $100 \%$. The maternal age was 28 (4) years old. The CRL was 66 (10) $\mathrm{mm}$, and the NT thickness was $1.80(0.5) \mathrm{mm}$. The distribution of fetal cases in each gestational week is shown in Fig. 5.

\section{Evaluation of intra-operator and inter-operator agreement}

Thirty ultrasonographic images in fetal facial midsagittal section were randomly selected from 380 fetuses that met the inclusion criteria to evaluate the reproducibility and feasibility of the measurement. The ICCs (95\% CI) of intra-operator 1 reproducibility of IFA, 


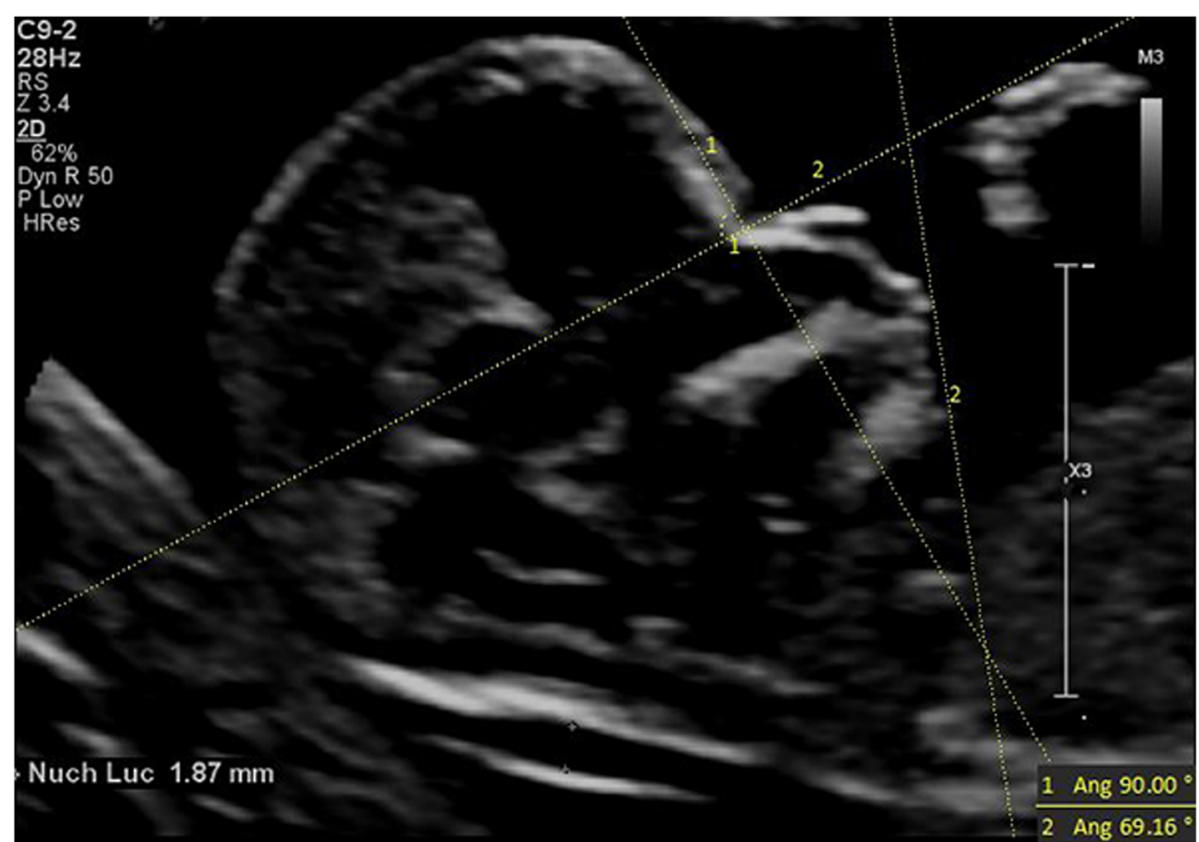

Fig. 1 The measurement of IFA $\left(69.16^{\circ}\right)$; 13 w2d, normal Chinese fetus

MNM angle, FMA, PL distance were 0.944 (0.886 0.973), 0.804 (0.629 0.902), $0.834 \quad(0.68 \sim 0.918)$ and 0.935 (0.868 0.969), respectively. The ICCs $(95 \% \mathrm{CI})$ of intra-operator 2 reproducibility of IFA, MNM angle, FMA, PL distance were 0.931 (0.857 0.967), 0.809 (0.637 0.904), $0.786(0.600 \sim 0.892)$ and 0.906 (0.813 $0.954)$, respectively. The ICCs $(95 \% \mathrm{CI})$ of interoperator reproducibility of IFA, MNM angle, FMA, PL distance were $0.885 \quad(0.663 \sim 0.953), 0.829 \quad(0.672 \sim$ $0.915), 0.77(0.511 \sim 0.891)$ and $0.844 \quad(0.68 \sim 0.925)$, respectively.

Table 1; Figs. 6a-d, 7a-d and 8a-d showed the BlandAltman analysis evaluating intra-operator and interoperator the agreement of measurement of IFA, MNM angle, FMA and PL distance. The reproducibility of these markers for intra-operator and inter-operator was good.

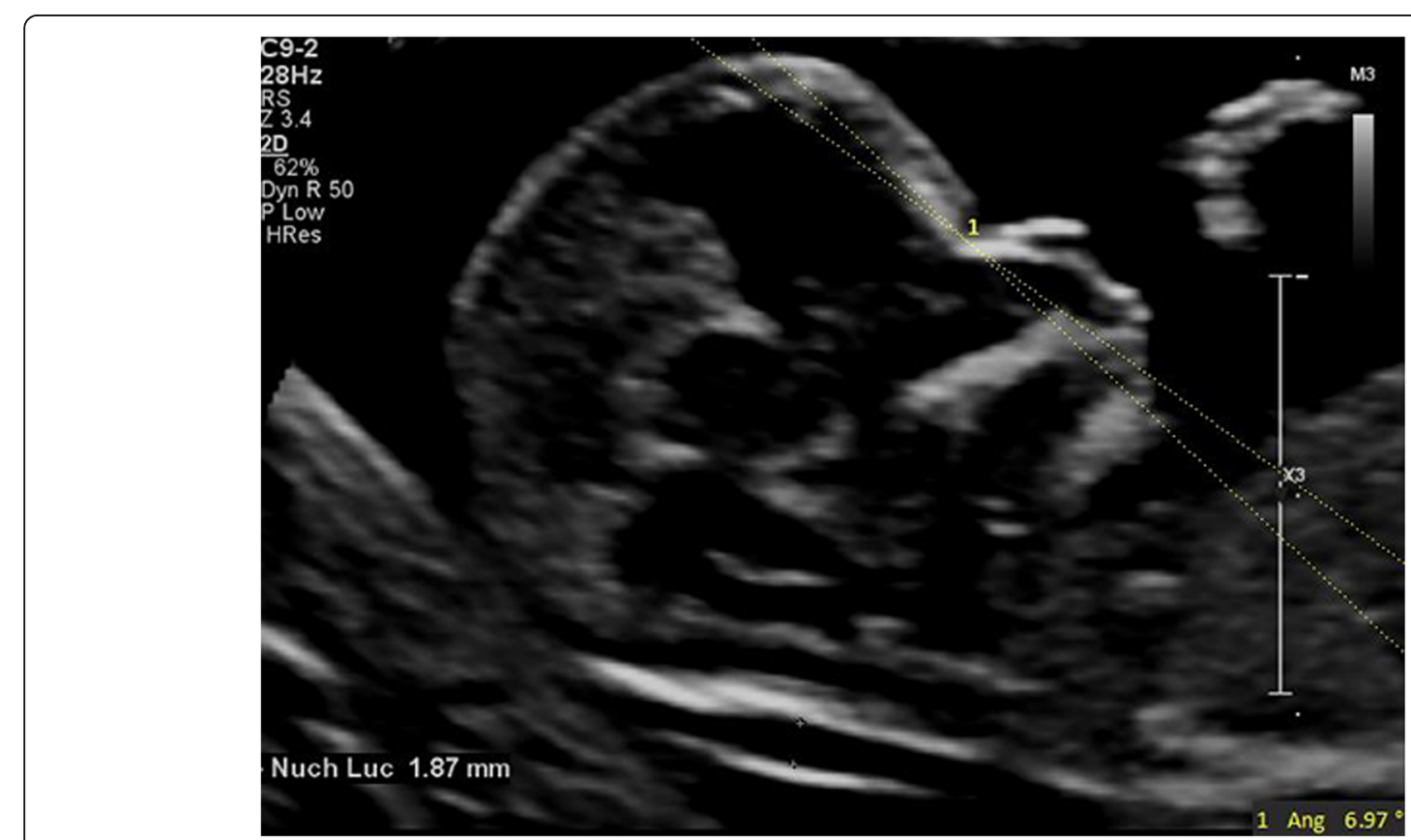

Fig. 2 The measurement of MNM angle $\left(6.97^{\circ}\right) ; 13$ w2d, normal Chinese fetus 


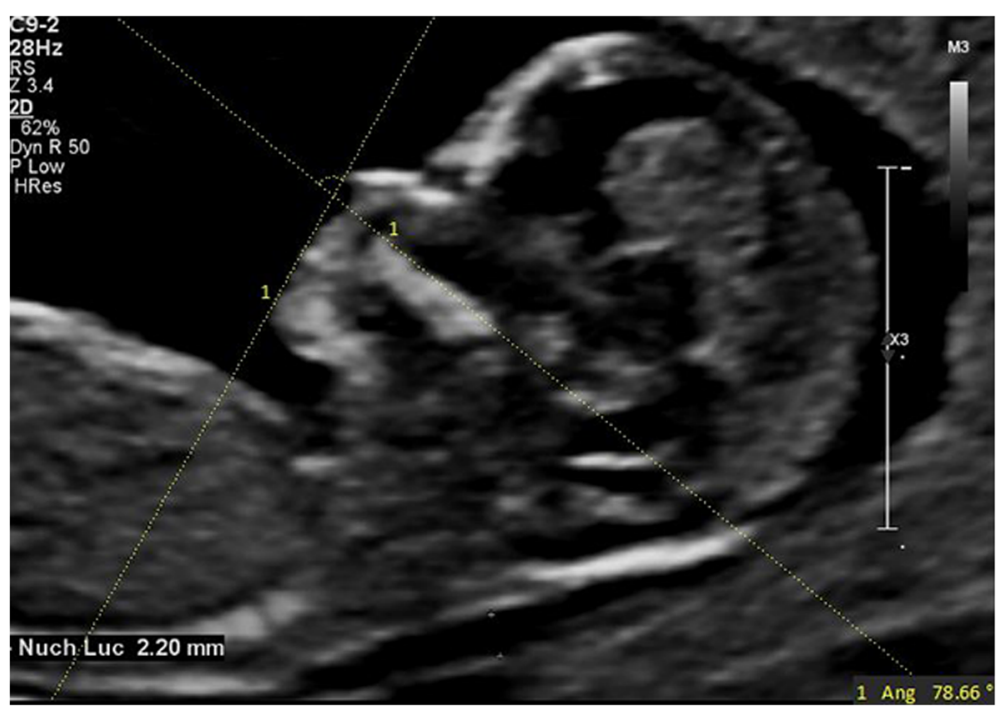

Fig. 3 The measurement of FMA $\left(78.66^{\circ}\right) ; 13 w 6 d$, normal Chinese fetus

\section{Correlation between fetal facial markers and CRL}

The measurement range of IFA was $55.9^{\circ} \sim 107.89^{\circ}\left(80.2^{\circ} \pm\right.$ $7.25^{\circ}$ ). IFA had significant negative correlation to CRL during the first trimester (IFA $=127.601-0.707^{*} \mathrm{CRL}, \mathrm{r}=-$ $0.598, p<0.001)$. IFA was Gaussian distributed, and its reference range was $65.99^{\circ} \sim 94.41^{\circ}$ (mean $\pm 1.96 \mathrm{SD}$ ).

The measurement range of MNM angle was $1.66^{\circ} \sim 9.21^{\circ}$ $\left(4.17^{\circ} \pm 1.19^{\circ}\right)$. The MNM angle had significant positive correlation to CRL during the first trimester (MNM angle $\left.=-4.112+0.123^{*} \mathrm{CRL}, \mathrm{r}=0.547, p<0.001\right)$. The MNM angle was Gaussian distributed, and the reference range of the MNM angle was $1.84^{\circ} \sim 6.50^{\circ}$ (mean $\pm 1.96 \mathrm{SD}$ ).

The measurement range of FMA was $56.29^{\circ} \sim 89.59^{\circ}$ $\left(75.36^{\circ} \pm 5.31^{\circ}\right)$. FMA depended significantly on CRL
$(\mathrm{FMA}=55.683+0.293 * \mathrm{CRL}, \mathrm{r}=0.339, \quad p<0.001) . \quad \mathrm{FMA}$ was Gaussian distributed, and the reference range was $64.95^{\circ} \sim 85.77^{\circ}$ (mean $\pm 1.96 \mathrm{SD}$ ).

The measurement range of PL distance was 1.53 $4.37 \mathrm{~mm}(2.78 \pm 0.54 \mathrm{~mm})$. The PL distance decreased with CRL (PL distance $=5.136-0.035^{\circ} \mathrm{CRL}, \mathrm{r}=-0.399, p<$ 0.001). The PL distance was Gaussian distributed, and its reference range was $1.72 \sim 3.84 \mathrm{~mm}$ (mean $\pm 1.96 \mathrm{SD})$.

\section{Discussion}

Trisomy 21, also known as Down Syndrome (DS), is the most common chromosomal abnormality and is accompanied by different degrees of mid-facial hypoplasia and

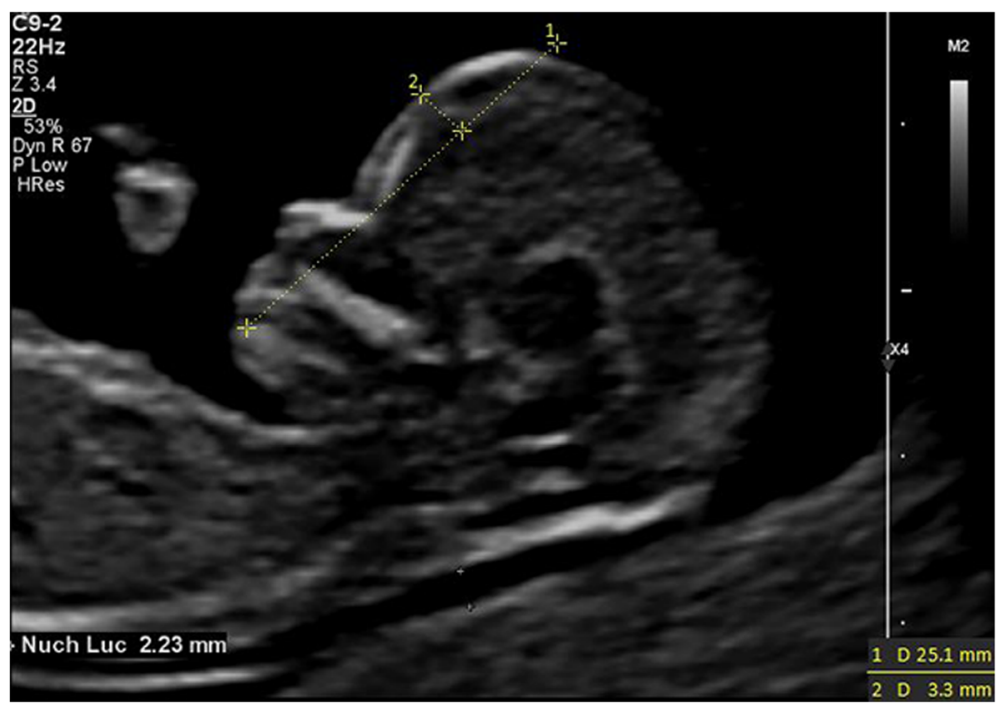

Fig. 4 The measurement of PL distance (3.3mm) 12w4d, normal Chinese fetus 


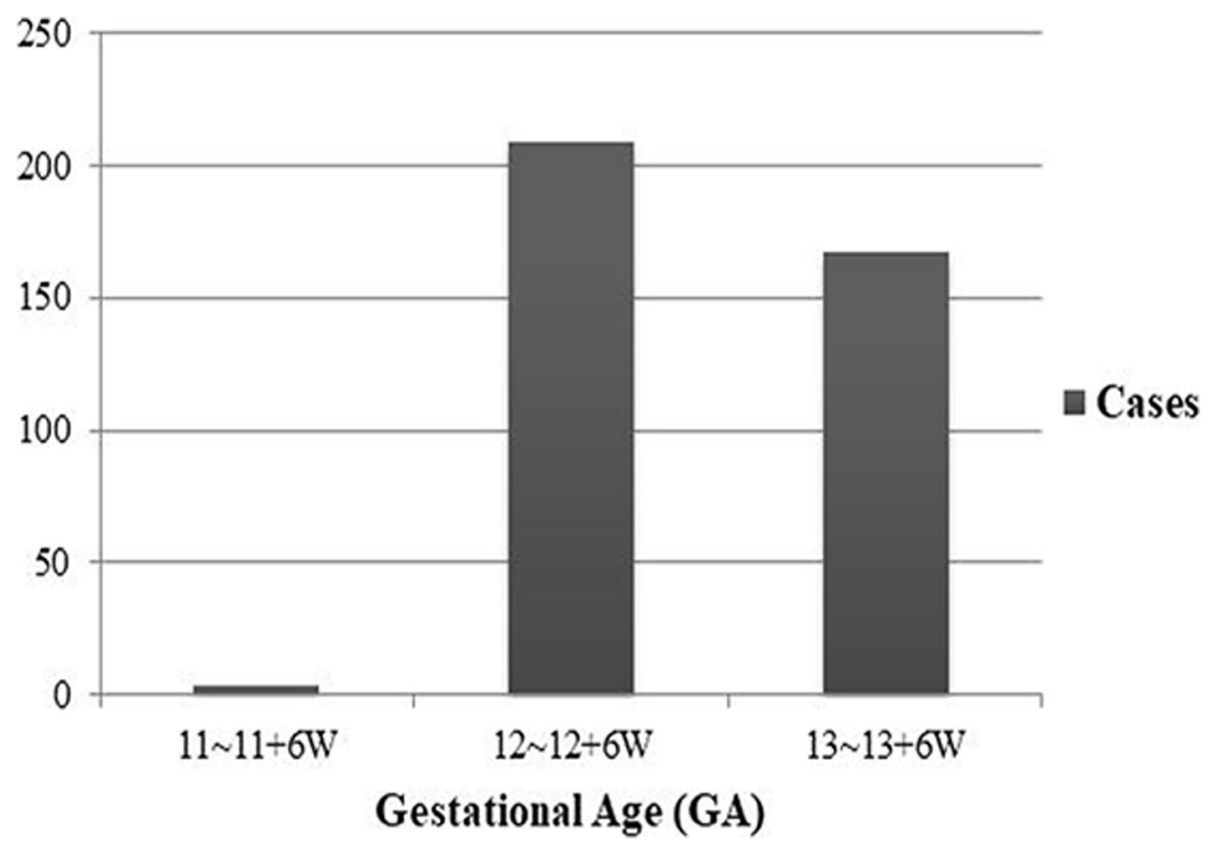

Fig. 5 The distribution of the cases of fetuses in each gestational age

skin edema [12, 13]. Compared to euploid fetuses, DS fetuses have typical facial features such as hypoplastic or absent nasal bones, thickened prenasal skin, shortening and dorsal displacement of the maxilla, et al. [14]. Most fetuses with trisomy 18 , the second most common chromosomal abnormality, have micrognathia [15] and CLP. The diagnosis of micrognathia is mainly subjective during the second and third trimester. In the meanwhile, CLP is the most common facial malformation. Although not fatal, it has great adverse impact on children and families involved. Moreover, $54 \%$ of CLP may associated with other anomalies or genetic syndromes [16], affecting about $1 \sim 2 / 1000$ live births [17].

With the rapid development of science and technology, NIPT (non-invasive prenatal test) has become the first choice for screening chromosomal aneuploidy due to its non-invasiveness, high sensitivity, and high specificity [18]. To some extent, the value of these facial markers in predicting aneuploidy was limited. NIPT has a high detection rate for DS, trisomy 18 and trisomy 13, but it cannot completely cover 23 pairs of chromosomes. The first trimester ultrasound screening could diagnosis some structural abnormalities such as CLP and micrognathia, and this advantage could not be replaced by NIPT. In this study, multiple facial markers reflected the relative position of the forehead, maxilla, and mandible were analyzed to establish their reference ranges, and these markers could further provide objective and quantitative criteria for the early detection of fetal facial anomalies and underlying genetic abnormalities.

The embryonic development of facial bones has its main characteristics. The maxilla and mandible begin to ossify from 8 weeks onward [19]. The maxilla is anatomically fused with the skull and grows forward with the development of brain tissue, while the mandible is connected to the skull through the temporomandibular joint. Therefore, the mandibular forward growth rate during the first trimester is slower than that of the maxilla [20]. From 20 weeks onward, the maxilla ossification has almost completed, and the developing fetal swallowing function accelerates the growth of mandible. After that, the position of facial bones is relatively constant, then fetal facial profile is basically formed [21].

Table 1 Intra-operator and inter-operator agreement of IFA, MNM angle, FMA and PL distance

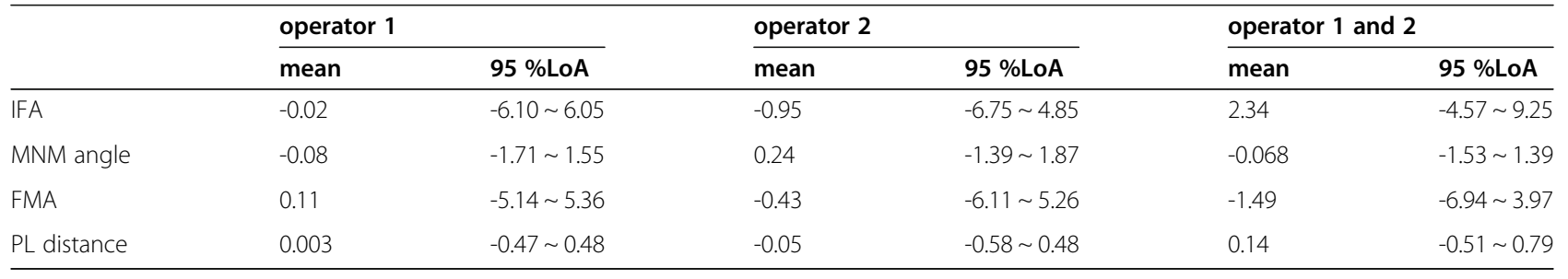




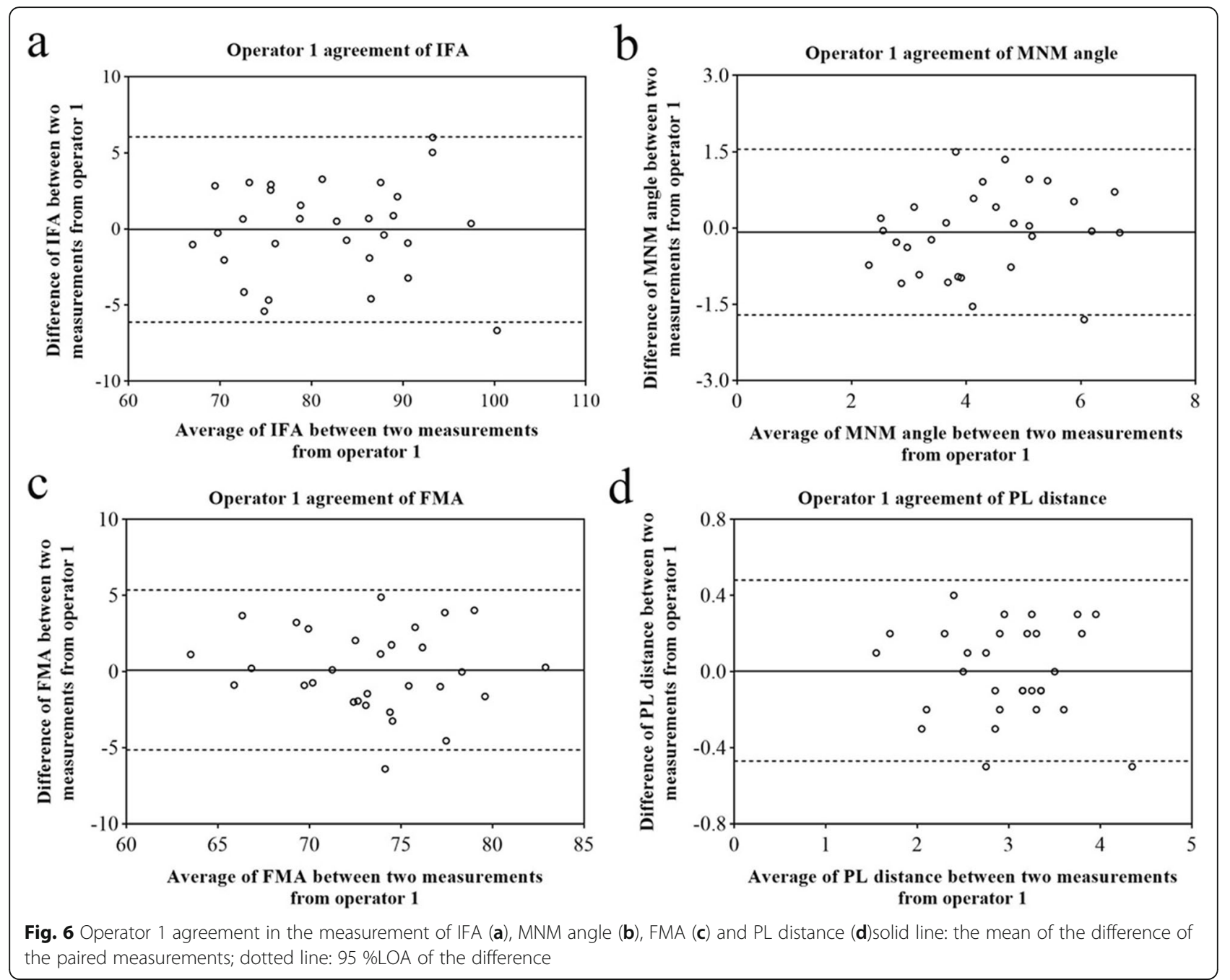

In 2002, Rotten et al. [7] studied 371 normal fetuses and 12 fetuses with mandible anomalies and first introduced the IFA to detect micrognathia. They found that the mean IFA of normal fetuses was $65.5^{\circ} \pm 8.13^{\circ}$ at $18 \sim$ 28 weeks' gestation, and it was constant during pregnancy. Using $49.2^{\circ}$ (average-2SD) as a cut-off, the IFA had a sensitivity of 1.0 , a specificity of 0.989 , a false positive rate of 0.011 to predict micrognathia. IFA could reflect the anterior and posterior position between the mandible and frontal bone to evaluate micrognathia, which was often associated with some genetic anomalies, such as Pierre-Robin syndrome, Stickler syndrome, trisomy 18 and trisomy 13 [1, 22, 23]. During the first trimester, we found that the mean IFA of normal fetuses was 80.2 (SD 7.25) ${ }^{\circ}$, and it decreased with CRL. This value was close to Tekesin et al. $\left(76.5^{\circ} \pm 6.30^{\circ}\right)$ [24] but larger than Rotten et al. [7]. The reason might be that the mandibular forward growth rate during the first trimester is slower than that of the forehead. While during the second trimester, the position of facial bones is relatively constant. Similar to our results, Orzechowski et al. [25] and Tekesin et al. [24] also reported the IFA decreased with CRL during the first trimester. According to their results, the abnormal IFA did not seem to be helpful for diagnosis of trisomy 21 [24, 25]. In our study, the reference range of IFA was $65.99^{\circ} \sim 94.41^{\circ}$. The possibility of micrognathia, which was relevant for the early detection of certain genetic syndromes, should be considered when IFA was less than $65.7^{\circ}$ (average-2SD). However, the clinical significance of this supposed value needs to be confirmed by large abnormal sample from multi-centers.

The MNM angle could reflect the relative position of the maxilla and mandible, further to evaluate fetal facial profile. De Jong-Pleij et al. [8] reported that the mean MNM angle was $13.5^{\circ}$ and independent of gestational age in the second and third trimester, making it a sensitive indicator for evaluating micrognathia and CLP. Vos et al. [26, 27] reported that the MNM angle had a definite implication for trisomy 21 and 

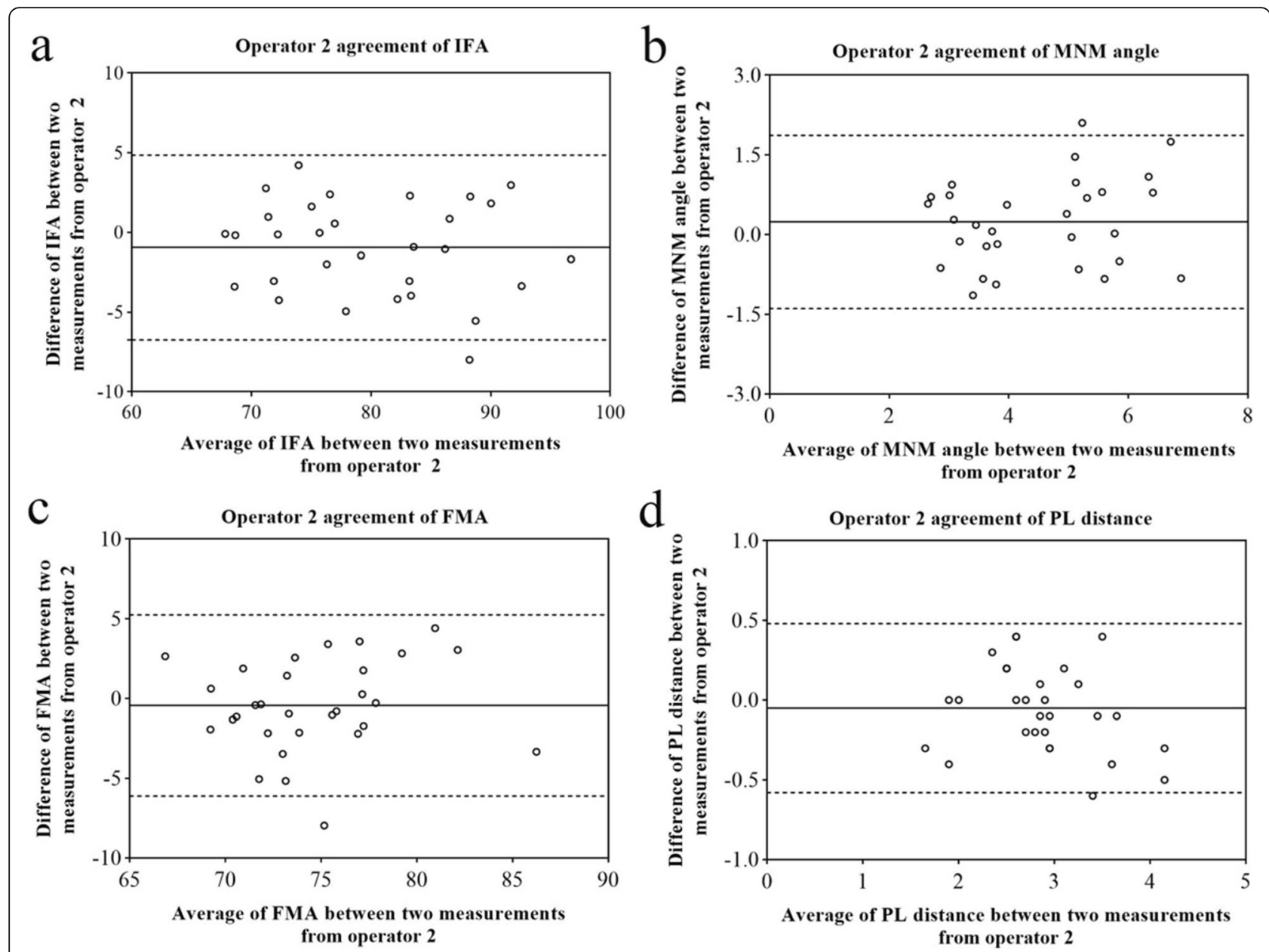

Fig. 7 Operator 2 agreement in the measurement of IFA (a), MNM angle (b), FMA (c) and PL distance (d)solid line: the mean of the difference of the paired measurements; dotted line: $95 \% \mathrm{LOA}$ of the difference

trisomy 18 during later stages of pregnancy. In our study, the mean MNM angle was 4.17 (SD 1.19) ', which increased with CRL. However, Ko et al. [28] found the MNM angle had a negative correlation with gestational age at $14 \sim 39$ weeks. Lu et al. [10] pointed out that the MNM angle did not change at $16 \sim 36$ weeks' gestation. Recently, Sun et al. [18] demonstrated that the MNM angle was higher in euploid fetuses than trisomy 21 fetuses during the first trimester. Further studies are necessary to investigate the relationship between the MNM angle and gestational age in order to diagnose more fetal facial abnormalities or chromosomal abnormalities.

FMA can directly reflect the relative position of the maxilla and mandible to evaluate fetal facial profile. In order to avoid the influence of the curvature of the vomer, Lu et al. [10] used the surface of anterior half of the maxilla as a reference line. Their research showed that FMA was related to gestational age which increased with gestation slightly $\left(1^{\circ} \sim 2^{\circ}\right.$ /week) from 16 weeks to $28 \sim 31$ weeks and then decreased minimally. It might be consistent with the allometric growth relationship between different parts of fetal face. We found that FMA increased with CRL, with the reference range of $64.95^{\circ} \sim 85.77^{\circ}$. Lu et al. [10] reported that the cut-off of FMA in detecting micrognathia was $66^{\circ}$ (average-2SD at 16 weeks), with the detection rate of $100 \%$ and false positive rate of $2.5 \%$. The value was similar to our study $\left(64.95^{\circ}\right)$. A large prospective cohort is needed to determine the diagnostic accuracy of FMA for micrognathia during the first trimester.

De Jong-Pleij et al. [29] showed that the mean PL distance at $27 \sim 36$ weeks' gestation was 2.8 (range $2.1 \sim$ 3.6) $\mathrm{mm}$, and $4 \mathrm{~mm}$ could be used as the upper limit of the normal for judging frontal bossing. The PL distance was the first objective quantitative indicator to assess frontal bossing, which was affected by the position of the mandible, nasion and frontal bone. In our study, the mean PL distance was $2.78 \pm 0.54 \mathrm{~mm}$, and it decreased 

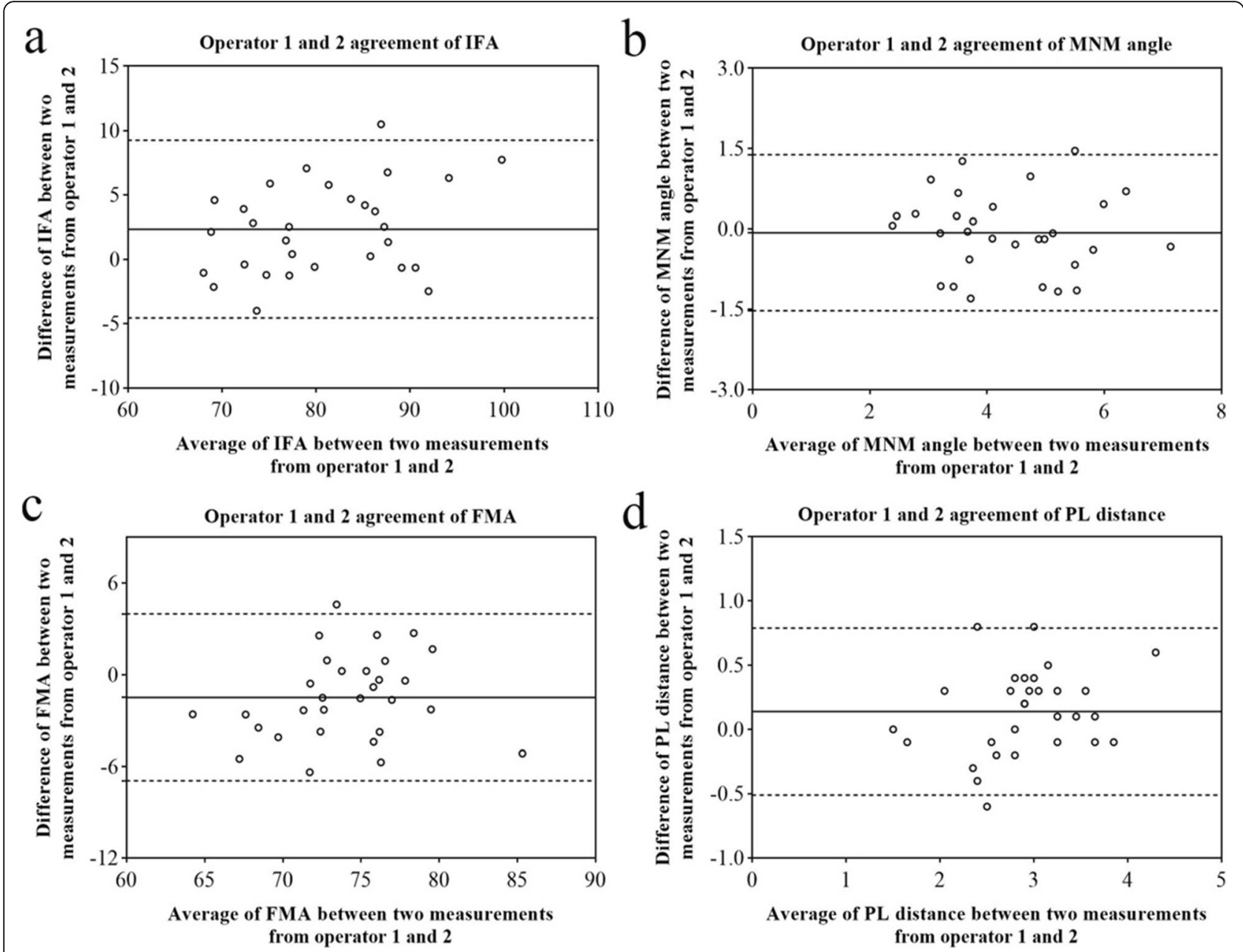

Fig. 8 Operator 1 and 2 agreement in the measurement of IFA (a), MNM angle (b), FMA (c) and PL distance (d)solid line: the mean of the difference of the paired measurements; dotted line: $95 \%$ LOA of the difference

with CRL, which was consistent with Bakker et al. [9]. This might be caused by forward movement of the maxilla and decrease in convexity of the forehead during the first trimester [20]. Bakker et al. [9] also pointed out that the PL distance was not the best ultrasound marker for aneuploidies.

There were some limitations in our study. Firstly, it is a retrospective study, and the static image selected from the first trimester ultrasound screening was to measure the NT thickness rather than observe facial abnormalities. Secondly, the same stored ultrasound image was used by the two operators to assess the inter-operator reproducibility, and thus accounted at least partly for the high ICC. Thirdly, facial abnormalities with or without aneuploidies were not included. In addition, all parameters were measured on $2 \mathrm{D}$ images, without the use of 3D reconstructed techniques. Some research $[7,14]$ showed that $3 \mathrm{D}$ technique could better obtain the true mid-sagittal section, but it took a long time. On the other hand, 2D ultrasound was the basis of
3D ultrasound. 2D measurements were reported to be the same reliable and accurate as $3 \mathrm{D}$ measurements in the measurement of facial marker [30, 31].

\section{Conclusions}

Intra-operator and inter-operator reproducibility for facial profile markers (IFA, MNM angle, FMA, PL distance) were good during the first trimester $\left(11 \sim 13^{+6}\right.$ weeks' gestation). It's feasible to measure these markers during the first trimester. The reference range of each marker was obtained through large sample data, and these markers were significantly related to CRL. If the measurement is not in this range, micrognathia and other facial abnormalities should be highly suspected. On this basis, further studies will be carried out to investigative the detection rate and false positive rate of these markers for facial abnormalities with or without aneuploidies. However, their clinical application shall be cautious. A large multi-center prospective cohort and enough positive cases are required. 


\section{Abbreviations}

CLP: Cleft lip and palate; CRL: Crown-rump length; CVS: Chorionic villus sampling; DICOM: Digital Imaging and Communications in Medicine; DS: Down Syndrome; FMA: Facial maxillary angle; FMF: Fetal Medicine Foundation; FPL: facial profile line; ICC: Intraclass correlation coefficient; IFA: Inferior facial angle; ISUOG: International Society of Ultrasound in Obstetrics and Gynecology; LOA: Limits of agreement; MNM: Maxilla-nasionmandible angle; NIPT: Non-invasive prenatal test; NT: Nuchal translucency; PL: Profile line distance; SD: Standard deviation; 2D-US: Two-dimensional ultrasound; 4D: Four-dimensional

\section{Acknowledgements}

We are grateful for the cooperation and support from all of our study participants. Thanks to all members in the Center for Medical Ultrasound, the Affiliated Suzhou Hospital of Nanjing Medical University, especially Dr. Bing Lu, Dr. Wei Jiang, Dr. Jingyi Hu, Dr. Hongmei Chang, Dr. Yaqi Tang, Dr. Lingling Sun, Miss. Yixin Yu, for their supports and follow-up.

\section{Authors' contributions}

CYJ, XLJ, LLY: Conceptualization; CYJ, LLY: Data collection and analysis; CYJ, XLJ: Manuscript writing; LLY, XDD: Funding acquisition, Project administration; CYJ, LLY, QP: Supervision; ZY, JZ, QL: Proof-read the draft. All authors of this paper have read and approved the final version submitted.

\section{Funding}

This study was sponsored by Jiangsu Provincial Medical Youth Talent (QNRC2016237), Jiangsu Provincial Maternal and Child Health Key Talent (FYC201746), Scientific Research on Health and Family Planning Project in Jiangsu Province (H201544), Suzhou Key Medical Center (Szzx201505), Suzhou Gusu Health Key Talent (GSWS2016072), and Suzhou Gusu Health Leading Talent (GSWS2019006).

\section{Availability of data and materials}

The datasets and code used and analyzed during the current study are available from the corresponding author on reasonable request.

\section{Declarations}

\section{Ethics approval and consent to participate}

The study was approved by the Ethics Committee of Suzhou Municipal Hospital (K2016038). Informed consents were obtained from all pregnant women.

\section{Consent for publication}

The manuscript is approved by all participants for publication.

\section{Competing interest}

The authors declare that they have no competing interests.

Received: 15 January 2021 Accepted: 20 April 2021

Published online: 24 April 2021

\section{References}

1. Bromley B, Benacerraf BR. Fetal micrognathia: associated anomalies and outcome. J Ultrasound Med. 1994;13:529-33.

2. Cao Y, Li Z, Rosenfeld JA, et al. Contribution of genomic copy-number variations in prenatal oral clefts: a multicenter cohort study. Genet Med. 2016;18:1052-5.

3. Otto C, Platt LD. Fetal growth and development. Obstet Gynecol Clin North Am. 1991;18:907-31.

4. Vayna AM, Veduta A, Duta S, et al. Diagnosis of Fetal Structural Anomalies at 11 to 14 Weeks. J Ultrasound Med. 2018;37:2063-73.

5. Souka AP, Pilalis A, Kavalakis I, et al. Screening for major structural abnormalities at the 11- to 14-week ultrasound scan. Am J Obstet Gynecol. 2006:194:393-6.

6. Salomon $\sqcup$, Alfirevic Z, Bilardo CM, et al. ISUOG practice guidelines performance of first-trimester fetal ultrasound scan. Ultrasound Obstet Gynecol.2013;41:102-13.

7. Rotten D, Levaillant JM, Martinez $H$, et al. The fetal mandible: a $2 D$ and $3 D$ sonographic approach to the diagnosis of retrognathia and micrognathia. Ultrasound Obstet Gynecol. 2002;19:122-30.
8. de Jong-Pleij EA, Ribbert LS, Manten GT, et al. Maxilla-nasion-mandible angle: a new method to assess profile anomalies in pregnancy. Ultrasound Obstet Gynecol. 2011;37:562-9.

9. Bakker M, Pace M, de Jong-Pleij E, et al. Prenasal Thickness, Prefrontal Space Ratio and Other Facial Profile Markers in First-Trimester Fetuses with Aneuploidies, Cleft Palate, and Micrognathia. Fetal Diagn Ther. 2018;43:231-40.

10. Lu J, Sahota DS, Poon LC, et al. Objective assessment of the fetal facial profile at second and third trimester of pregnancy. Prenat Diagn. 2019;39: 107-15.

11. Bland JM, Altman DG. Statistical methods for assessing agreement between two methods of clinical measurement. Lancet. 1986;1:307-10.

12. Dagklis $T$, Borenstein $M$, Peralta CF, et al. Three-dimensional evaluation of mid-facial hypoplasia in fetuses with trisomy 21 at $11+0$ to $13+6$ weeks of gestation. Ultrasound Obstet Gynecol. 2006;28:261-5.

13. Serville F, Battin J, Leng JJ, et al. [Neck edema. An echographic sign of trisomy 21 in pregnancy]. Arch Fr Pediatr. 1986;43:487-8.

14. Yazdi B, Sonek J, Oettling C, et al. Prefrontal space ratio in second- and thirdtrimester screening for trisomy 21. Ultrasound Obstet Gynecol. 2013;41:262-6.

15. Nicolaides KH, Salvesen DR, Snijders RJ, et al. Fetal facial defects: associated malformations and chromosomal abnormalities. Fetal Diagn Ther. 1993;8:1-9.

16. Maarse W, Rozendaal AM, Pajkrt E, et al. A systematic review of associated structural and chromosomal defects in oral clefts: when is prenatal genetic analysis indicated?. J Med Genet.2012;49:490-8.

17. Calzolari E, Pierini A, Astolfi G, et al. Associated anomalies in multimalformed infants with cleft lip and palate: An epidemiologic study of nearly 6 million births in 23 EUROCAT registries. Am J Med Genet A. 2007; 143A:528-37.

18. Sun $Y$, Zhang $L$, Dong $D$, et al. First-trimester screening for trisomy 21 via an individualized nomogram. Ultrasound Obstet Gynecol. 2020;21.

19. Morimoto N, Ogihara N, Katayama K, et al. Three-dimensional ontogenetic shape changes in the human cranium during the fetal period. J Anat. 2008; 212:627-35.

20. Trenouth MJ. Shape changes during human fetal craniofacial growth. J Anat. 1984;139:639-51

21. Som PM, Naidich TP. Illustrated review of the embryology and development of the facial region, part 2: Late development of the fetal face and changes in the face from the newborn to adulthood. AJNR Am J Neuroradiol. 2014;35:10-8.

22. Merz E, Abramovicz J, Baba K, et al. 3D imaging of the fetal face recommendations from the International 3D Focus Group. Ultraschall Med. 2012;33:175-82.

23. Luedders DW, Bohlmann MK, Germer U, et al. Fetal micrognathia: objective assessment and associated anomalies on prenatal sonogram. Prenat Diagn. 2011;31:146-51.

24. Tekesin I, Graupner O. Measurement of inferior facial angle and prefrontal space ratio in first trimester fetuses with aneuploidies: a retrospective study. J Perinat Med. 2019:47:969-78.

25. Orzechowski M, Knafel A, Banas T, et al. Ultrasound evaluation of inferior facial angle (IFA) in a population of normal fetuses at 11-13 weeks $(+6$ days) gestation. Przegl Lek. 2017;74:8-12.

26. Vos Fl, de Jong-Pleij EA, Bakker $\mathrm{M}$, et al. Facial profile markers in secondand third-trimester fetuses with trisomy 18. Ultrasound Obstet Gynecol. 2015;46:66-72.

27. Vos Fl, De Jong-Pleij EA, Bakker M, et al. Trends in Serial Measurements of Ultrasound Markers in Second and Third Trimester Down Syndrome Fetuses. Fetal Diagn Ther. 2015;38:48-54.

28. Ko HS, Lee UY, Choi SK, et al. Craniofacial inclination at 14 to 39 weeks' gestation in normal Korean fetuses. J Ultrasound Med. 2012;31:569-76.

29. de Jong-Pleij EA, Ribbert $L S$, Pistorius $L R$, et al. The fetal profile line: a proposal for a sonographic reference line to classify forehead and mandible anomalies in the second and third trimester. Prenat Diagn. 2012;32:797-802.

30. Alphonse J, Cox J, Clarke JL, et al. Frontomaxillary facial angle measurement at 11-14 weeks: assessment of interobserver and intraobserver agreement in 2D and 3D imaging. Fetal Diagn Ther. 2013;34:90-5.

31. Alphonse J, Cox J, Clarke $J$, et al. Frontomaxillary facial angle measurement in trisomy 21 and euploid fetuses: two- and three-dimensional assessment during routine first trimester screening. Fetal Diagn Ther. 2014;36:183-9.

\section{Publisher's Note}

Springer Nature remains neutral with regard to jurisdictional claims in published maps and institutional affiliations. 